\title{
Reciprocal Changes in Maternal and Fetal Metabolism of Corticosterone in Rat During Gestation
}

\author{
K.Vagnerová, PhD, Z.Vacková, MSc, P. Klusoňová, MSc, F. Staud, PhD, \\ M. Kopecký, PhD, P. Ergang, MSc, I. Mikšík, PhD, and J. Pácha, PhD
}

\begin{abstract}
Objective. The objective of this study was to investigate the role of $11 \beta$-hydroxysteroid dehydrogenases (11HSD1 and 11HSD2) in determining the fetal concentration of glucocorticoids. Methods. The expression patterns for $m R N A$ abundance, protein level, and enzyme activities of placental and fetal 11HSD1 and 11HSD2 were assessed from embryonic day 13 (E13) to day 21 (E21; term E22). The transplacental passage of maternal corticosterone and its contribution to fetal glucocorticoids was also studied. Results. Placental 11HSD1 mRNA decreased between days E13 and E14 and then remained at much lower values up to E21. Similarly, NADP+-dependent $11 \beta$-oxidation and 11-reduction were lower in late gestation. In contrast, placental 11HSD2 $m R N A$ and protein decreased between E13 and E21. Dithiothreitol increased the activity of 11HSD2 and the output of 11-dehydrocorticosterone into fetal circulation. The fetal activity of 11HSD1 increased and 11HSD2 decreased between E16 and E21. Conclusions. The final third of gestation is accompanied by reciprocal changes in placental and fetal metabolism of corticosterone due to changes in 11HSD1 and 11HSD2 not only at the level of transcription but also at a posttranslational level.
\end{abstract}

KEY wORDs: Placenta, fetal development, metabolism of glucocorticoids, corticosterone.

$\checkmark$ lucocorticoids are hormones that play an important regulatory role during the maturation of fetal organs and the timing of parturition. ${ }^{1,2}$ Fetal glucocorticoids can come from several sources, in particular through glucocorticoid secretion by the fetal adrenal glands after the activation of the fetal hypothalamicpituitary-adrenal axis, ${ }^{2}$ by the local production of glucocorticoids in the fetal membranes ${ }^{3}$ and by the transplacental transfer of maternal glucocorticoids to the fetus. ${ }^{4-6}$ Although steroids can be considered to cross the placenta easily, the levels of glucocorticoid hormones are much

From the Institute of Physiology, Czech Academy of Sciences, Prague (KV, PK, MK, PE, IM, JP) and Faculty of Pharmacy, Charles University, Hradec Králové (ZV, FS, MK), Czech Republic.

This study was supported by grants KJB5011402 and AV0Z50110509 from Academy of Sciences and by grant no. 102/2006/C/FaF from the Grant Agency of Charles University.

Address correspondence to:J. Pácha, Institute of Physiology, Czech Academy of Sciences, Vídenská 1083, 14220 Prague 4-Kr?, Czech Republic. E-mail: pacha@biomed.cas.cz.

Reproductive Sciences Vol. 15 No. 9 November $2008921-931$

DOI. 10.1177/1933719108319161

(C) 2008 by the Society for Gynecologic Investigation lower in fetuses than in maternal blood for much of gestation. ${ }^{7-9}$ The difference between the maternal and fetal plasma concentration of glucocorticoids is ascribed to the placenta. It protects the fetuses against maternal cortisol or corticosterone by oxidation of these hormones to their biologically inactive 11-oxo derivatives cortisone and 11-dehydrocorticosterone via the activity of the enzyme $11 \beta$-hydroxysteroid dehydrogenase (11HSD). ${ }^{10}$ Importantly, mutations in the gene of this enzyme in humans are associated with low birth weight and exposure of pregnant rats to blockers that inhibit the activity of this enzyme reduces offspring birth weight and produces long-term metabolic and neuroendocrinic changes that lead to increases in adult blood pressure, glucose levels, and hypothalamic-pituitary-adrenal axis activity, that is, prenatal exposure to excess glucocorticoids might link fetal growth with adult pathophysiology. ${ }^{11}$

Two functionally distinct types of 11HSD exist - the $\mathrm{NAD}^{+}$-dependent enzyme (11HSD2), which operates only as an oxidase and catalyzes the conversion of cortisol and corticosterone to cortisone, and 11-dehydrocorticosterone and the $\mathrm{NADP}^{+} / \mathrm{NADPH}$-dependent enzyme (11HSD1), which has both oxidase and reductase activities 
and catalyzes the bidirectional interconversion between cortisol and cortisone or corticosterone and 11-dehydrocorticosterone. The expression of both isoforms has been demonstrated and characterized to varying degrees in human, ${ }^{4,12,13}$ baboon, ${ }^{14,15}$ rat, ${ }^{16-18}$ mouse, ${ }^{19,20}$ and porcine placenta. ${ }^{21}$

In rat placenta, both 11HSD1 and 11HSD2 are expressed in a developmentally programmed manner in 2 functionally distinct placental zones- the labyrinth zone in which both maternal and fetal vessels are found and in the basal zone, located deeper than the labyrinth. ${ }^{17,18}$ The coexpression of both types of 11HSDs raise the possibility that the placenta is able to change its placental metabolic capacity not only to exclude maternal glucocorticoids from the fetus but also to modulate the access of maternal glucocorticoids to the fetal compartment. In addition, our recent data indicate that rat placenta forms a potent but incomplete barrier to maternal corticosterone. ${ }^{6}$ However, the definitive role of the placenta in the translocation of maternal corticosterone throughout gestation remains unknown, as does the relationship between placental and fetal 11HSD metabolism in determination the ratio of active and biologically inert glucocorticoids in fetal circulation. Therefore, this study was undertaken to explore the effect of placental and fetal glucocorticoid metabolism on fetal plasma glucocorticoids. For this purpose, we assessed the developmental patterns of 11HSD1 and 11HSD2 together with the transplacental transfer of maternal corticosterone and its contribution to fetal glucocorticoids.

\section{MATERIALS AND METHODS}

\section{Animals}

Wistar rats (Institute of Physiology, Czech Academy of. Sciences, Prague) were housed in a room with a controlled light cycle (12-hour light/12-hour dark) and temperature $\left(22^{\circ} \mathrm{C}\right)$ with free access to standard laboratory chow and tap water. The females were mated with a male for 1 night and the next day was taken as day 0 of pregnancy if spermatozoa were found in the vaginal smears. Placentae were used from rats on days E13, E14, E16, E19, and E21 of gestation. The rats used for infusion experiments in vivo and for dually perfused placenta in vitro were fasted before the experiments and anesthetized with pentobarbital (Nembutal; Abbott Laboratories, North Chicago, IL) in a $40 \mathrm{mg} / \mathrm{kg}$ dose administered into the tail vein. All other rats were killed by cervical dislocation and the placenta removed, free of fetal membrane. The procedures were approved by the Czech
Academy of Sciences Animal Care and Use Committee and the Ethical Committee of the Faculty of Pharmacy, Charles University, and were carried out in accordance with the Guide for the Care and Use of Laboratory Animals, and the European Convention for the Protection of Vertebrate Animals used for Experimental and other Scientific Purposes.

\section{Transplacental Passage of $\left[{ }^{3} \mathrm{H}\right]$ Corticosterone in Rats In Vivo}

To evaluate the transplacental passage of corticosterone and the role of 11HSD in this process, infusion studies using $\left[{ }^{3} \mathrm{H}\right]$ corticosterone were carried out on days E16 and E21 of gestation. The carotid artery and jugular vein were cannulated for blood sampling and isotope infusion, respectively. Rats received a priming dose of $\left[{ }^{3} \mathrm{H}\right]$ corticosterone $(5 \mu \mathrm{Ci} / 0.5 \mathrm{~mL} 0.9 \% \mathrm{NaCl})$ and were then infused with $\left[{ }^{3} \mathrm{H}\right]$ corticosterone $(0.5 \mu \mathrm{Ci} / \mathrm{min})$ for 60 minutes. Preliminary experiments indicated the radioactivity in blood plasma of the jugular vein remained constant after 30 minutes and this time was defined as the sample time when steady-state concentration had been attained. Hence, blood and fetus samples were taken for further analysis 60 minutes after the onset of the isotope infusion and 30 minutes after steady-state concentration was reached. The blood was collected into heparinized tubes, centrifuged at $3000 \times g$ for 10 minutes and the plasma stored at $-70^{\circ} \mathrm{C}$ until analyzed. Immediately after blood sampling the fetuses were dissected, frozen in liquid nitrogen and stored at $-70^{\circ} \mathrm{C}$ until analysis. Estimation of the total radioactivity was done in maternal blood samples and in homogenates of fetuses treated with Solvable tissue solubilizer (Perkin Elmer, Welleslay, MA).

To determine the corticosterone/11-dehydrocorticosterone ratio, the samples were extracted with ethyl acetate. Briefly, internal standard $\left[{ }^{3} \mathrm{H}\right]$ progesterone and radioinert corticosterone, 11-dehydrocorticosterone, and progesterone were added to the samples of blood plasma and tissue homogenate (in $0.1 \mathrm{~mol} / \mathrm{L}$ phosphate-buffered saline), mixed, and extracted with ethyl acetate (1 vol sample $/ 5$ vol solvent). The mixture was centrifuged at $3000 \times g$, the organic layer removed, washed with 0.1 $\mathrm{mol} / \mathrm{L} \mathrm{NaOH}$, then with water, centrifuged again and the supernatant transferred to a glass vial. The extraction of the sample was repeated 3 times, the organic layers were combined, dried under nitrogen at $37^{\circ} \mathrm{C}$ and stored at $-20^{\circ} \mathrm{C}$ until high-performance liquid chromatography (HPLC) analysis. 


\section{Dual Perfusion of Rat Placenta}

To investigate the effect of dithiotreitol (DTT) on the conversion capacity of 11HSD2, the method of dually perfused rat placenta from day 21 of gestation was used as described previously. ${ }^{6}$ Briefly, the placenta was excised and submerged in heated Ringer saline. A catheter was inserted into the uterine artery proximal to the blood vessel supplying the selected placenta and connected with a peristaltic pump. Krebs' perfusion liquid containing $1 \%$ dextran was brought from the maternal reservoir at a rate of $1 \mathrm{~mL} / \mathrm{min}$. The uterine vein, including the anastomoses to other fetuses, was ligated behind the perfused placenta and cut so that maternal solution could leave the perfused placenta. The selected fetus was separated from the neighboring ones by ligatures. The umbilical artery was catheterized using a 24-gauge catheter and connected with the tubing through which the fetal perfusion liquid from the fetal reservoir was supplied at a rate of $0.5 \mathrm{~mL} / \mathrm{min}$. The umbilical vein was catheterized in a similar manner and the selected fetus was removed. Before the start of each experiment, the fetal vein effluent was collected into preweighed glass vials to check for possible leakage of perfusion solutions from the placenta. Where leakage was found the experiment was terminated. Maternal and fetal perfusion pressures were monitored continuously throughout the perfusion experiments.

Corticosterone and $\left[{ }^{3} \mathrm{H}\right]$ corticosterone as a tracer were brought to the perfused placenta via the uterine artery immediately after catheterization. The final concentration of corticosterone in the maternal reservoir was $50 \mathrm{nmol} / \mathrm{L}$, which corresponds to the physiological values of unbound corticosterone in rat during the last week of gestation..$^{22}$ After a 10 -minute delay to achieve steadystate conditions, samples were collected at 10-minute intervals from the fetal umbilical vein. After the first sample was collected, DTT was added to the maternal reservoir to a concentration of 0.5 or $5 \mathrm{mmol} / \mathrm{L}$. After a 10-minute delay to reestablish steady state, collection of the second 10-minute interval sample was initiated. Samples were analyzed for $\left[{ }^{3} \mathrm{H}\right]$ corticosterone and $\left[{ }^{3} \mathrm{H}\right] 11$-dehydrocorticosterone by HPLC. The conversion capacity of placental $11 \beta$-oxidation was expressed as the ratio of 11-dehydrocorticosterone (metabolite) concentration to the concentration of total corticosteroids (corticosterone and 11-dehydrocorticosterone) in the fetal effluent.

\section{Measurement of 11HSD Activity in Tissue Homogenates}

Whole placentae or the whole fetuses of different days of gestation were homogenized in ice-cold buffer containing $200 \mathrm{mmol} / \mathrm{L}$ sucrose and $10 \mathrm{mmol} / \mathrm{L}$ Tris/ $\mathrm{HCl}$ at $\mathrm{pH}$ 8.5 (1:9 weight/vol) using a Polytron homogenizer (Kinematica AG, Littau, Switzerland). The homogenates were centrifuged at $1000 \times g$ for 10 minutes at $4^{\circ} \mathrm{C}$, the protein concentration determined by the Coomassie blue method, and the homogenates used immediately for the measurement of 11HSD activity.

11HSD2 activity was measured as the $\mathrm{NAD}^{+}$dependent oxidation of corticosterone in a radiometric conversion assay as reported previously. ${ }^{23}$ Briefly, the conversion of $\left[{ }^{3} \mathrm{H}\right]$ corticosterone (final concentration 14.5 $\mathrm{nmol} / \mathrm{L})$ to $\left[{ }^{3} \mathrm{H}\right] 11$-dehydrocorticosterone was measured in an incubation buffer $(100 \mathrm{mmol} / \mathrm{L} \mathrm{KCl}, 50 \mathrm{mmol} / \mathrm{L}$ Tris/HCl; $\mathrm{pH} 8.5)$ containing $400 \mu \mathrm{mol} / \mathrm{L} \mathrm{NAD}^{+}$. In some experiments the incubation buffer also contained a reducing agent, DTT at concentrations of 0.5 to 10.0 $\mathrm{mmol} / \mathrm{L}$. 11HSD1 was measured as the conversion of $\left[{ }^{3} \mathrm{H}\right] 11$-dehydrocorticosterone to $\left[{ }^{3} \mathrm{H}\right]$ corticosterone in the presence of $400 \mu \mathrm{mol} / \mathrm{L} \mathrm{NADPH}$ and a NADPHregenerating system $(1.3 \mathrm{mmol} / \mathrm{L}$ glucose-6-phosphate, 2 U glucose-6-phosphate dehydrogenase) or as the oxidation of $\left[{ }^{3} \mathrm{H}\right]$ corticosterone to $\left[{ }^{3} \mathrm{H}\right] 11$-dehydrocorticosterone in the presence of $400 \mu \mathrm{mol} / \mathrm{L} \mathrm{NADP}^{+}$. In both cases, the incubation buffer contained $100 \mathrm{mmol} / \mathrm{L} \mathrm{KCl}$, $50 \mathrm{mmol} / \mathrm{L}$ Tris/ $\mathrm{HCl}$ and was $\mathrm{pH}$ 7.5. The velocities of the reaction were linear within the periods of incubation used. The reactions were stopped by cooling and the samples were extracted with a Sep-Pak $\mathrm{C}_{18}$ cartridge and stored. The steroids were quantified by HPLC.

\section{Analysis of Steroids}

The separation and quantification of unlabelled and $\left[{ }^{3} \mathrm{H}\right]$-labeled steroids were conducted by HPLC as described previously. ${ }^{6,24}$ Briefly, the steroids were analyzed by an Agilent HPLC 1100 system (Agilent, Palo Alto, CA) with a Lichrospher 100 RP-18 column (125 $\times 4 \mathrm{~mm}$; Merck, Darmstadt, Germany) and linear methanol-water gradient from 42:58 ( $\mathrm{vol} / \mathrm{vol}$ ) to $62: 38$ (vol/vol) at 15 minutes followed by isocratic washing with $100 \%$ methanol for 10 minutes. The flow rate was $1.0 \mathrm{~mL} / \mathrm{min}$ and the column temperature was held at $45^{\circ} \mathrm{C}$. An Agilent 1100 ultraviolet absorbance detector 
Table 1. Primers Used for Reverse Transcriptase-Polymerase Chain Reaction

\begin{tabular}{lll}
\hline & \multicolumn{1}{c}{ Forward } & \multicolumn{1}{c}{ Reverse } \\
\hline 11HSD1 & GAGTTCAGACCAGAAATGCTCC & TGTGTGATGTGATTGAGAATGAGC \\
11HSD2 & CCGGTTGTGACACTGGTTTTG & GGGGTATGGCATGTCTCCTG \\
\hline
\end{tabular}

(at $254 \mathrm{~nm}$ ) and Radiomatic $150 \mathrm{TR}$ radioactivity detector (Packard, Downers Grove, IL) with a flow cell and Ultima-Flo $\mathrm{M}$ scintillation cocktail (Perkin Elmer, Boston, MA; flow rate $3 \mathrm{~mL} / \mathrm{min}$ ) were used for the detection and quantification of non-radioactive and radioactive steroids, respectively.

\section{Reverse Transcription and Real-Time RT-PCR}

Total RNA was extracted from frozen placenta samples by the guanidine thiocyanate method. To remove contamination by genomic DNA, the samples of isolated RNA were treated with DNase (Promega, Madison, WI) following the standard protocol. First strand cDNA was synthesized using $5 \mu \mathrm{g}$ of RNA and M-MLV (Invitrogen, Lofer, Austria) as described earlier. ${ }^{6}$ Quantitative reverse transcriptase polymerase chain reaction (RTPCR) was used to determine the mRNA abundances of 11HSD1, 11HSD2, and $\beta$-actin using a Fast Start DNA Master Sybr Green I kit (Roche, Mannheim, Germany), LightCycler instrument (Roche) and the primers listen in Table 1.The PCR was performed in duplicates in a total volume of $10 \mu \mathrm{L}$ containing $1 \mu \mathrm{L}$ of 10 -fold diluted cDNA; $3 \mathrm{mmol} / \mathrm{L}$ (11HSD1), $4 \mathrm{mmol} / \mathrm{L}$ (11HSD2), or $5 \mathrm{mmol} / \mathrm{L}$ ( $\beta$-actin) $\mathrm{MgCl}_{2} ; 0.5 \mu \mathrm{mol} / \mathrm{L}$ of each primer and PCR reaction mix $(1 \times)$. The LightCycler was programmed as follows: preincubation and denaturation of the template cDNA for 10 minutes at $95^{\circ} \mathrm{C}$ followed by 45 cycles of amplification at $95^{\circ} \mathrm{C}$ for 15 seconds, $55^{\circ} \mathrm{C}$ for 10 seconds (11HSD1, $\beta$-actin), or $60^{\circ} \mathrm{C}$ for 5 seconds (11HSD2), $72^{\circ} \mathrm{C}$ for 15 seconds (11HSD1, $\beta$-actin) or 20 seconds (11HSD2). A melting analysis was performed after each elongation. Quantification was performed using standard curves for each pair of primers from serial dilutions of kidney cDNA containing all 3 transcripts. The results were calculated as the relative expression of 11HSD1 mRNA or 11HSD2 mRNA to $\beta$-actin mRNA.

\section{Western Blotting Analysis}

Western blots were performed as described previously. ${ }^{6}$ Briefly, the placenta and kidney (which acted as a positive control) were homogenized, centrifuged at $400 \times g$ for 10 minutes and the supernatant centrifuged again at 100 $000 \times g$ for 60 minutes. The pellets were resuspended and sonicated in Laemmli buffer containing $2 \% \beta$-mercaptoethanol, boiled for 3 minutes and then stored at $-20^{\circ} \mathrm{C}$ until used for electrophoretic analysis.

The proteins were separated by $10 \%$ SDS-polyacrylamide gel electrophoresis and electroblotted in a semidry blotting system. The blots were incubated with sheep antirat 11HSD2 polyclonal antibody (Chemicon International, Inc, Temecula, CA) and subsequently incubated with peroxidase-conjugated rabbit anti-sheep immunoglobulin G (Pierce Biotechnology, Inc, Rockford, IL). The protein bands were visualized using Super Signal West Femto substrate (Pierce) and detected with a LAS-1000 luminiscence analysing system (Fuji, Tokyo, Japan). The band of approximately $40 \mathrm{kDa}$, corresponding to the known molecular mass of rat 11HSD2 was clearly visible in all specimens tested.

Despite the clear expression of 11HSD1 mRNA and 11-reductase activity in placental tissue, no specific signal for the 11HSD1 protein was measurable by immunoblotting at any stage of gestation examined, although several commercially accessible anti-rat 11HSD1 antibodies were tested (Alpha Diagnostics, Cayman Chemicals, Santa Cruz Biotechnology, US Biological) and some of them gave a positive signal with rat liver.

\section{Immunocytochemistry of Placental 11HSD2}

Sheep anti-rat polyclonal antibody raised against 11HSD2 was purchased from Chemicon Int. (Temecula, CA). Rat placentae were fixed in $4 \%$ paraformaldehyde $\left(4^{\circ} \mathrm{C}\right)$ at pH 7.4 (Sigma-Aldrich, Steinheim, Germany). The tissue samples were paraffin-embedded and then 5 to 
$6 \mu \mathrm{m}$ sections were cut on a Leica DSC1 rotating disk microtome (Leica Microsystems GmbH, Nussloch, Germany). Endogenous peroxidase activity was blocked with $3 \% \mathrm{H}_{2} \mathrm{O}_{2}$ in phosphate-buffered saline (PBS) solution for 15 minutes. For heat-induced antigen retrieval, the slides were boiled in $0.1 \mathrm{~mol} / \mathrm{L}$ citrate buffer $(\mathrm{pH}$ 6.0) for 15 minutes in a microwave oven at $750 \mathrm{~W}$. Slides were incubated with primary antibody diluted 1:1000 in PBS solution supplemented with $5 \%$ bovine serum albumin for 15 to 18 hours (overnight) at $4^{\circ} \mathrm{C}$.A streptavidin-biotin system using a biotinylated secondary antibody (donkey anti-sheep Ig; The Binding Site, Birmingham, UK), followed by incubation with a Vectastain ABC Kit (Vector Laboratories, Inc, Burlingame, CA) and diaminobenzidine (DAKOCytomation) was used as a chromogen for signal visualization. The sections were counterstained with haematoxylin. As a control for background staining, the slides were treated in the same manner, except that PBS solution was substituted for the primary and/or secondary antibody. The stained slides were examined using computer image analysis (light microscope Olympus AX70, Japan; digital camera PixeLINK PL-A642, Vitana Corp, USA; LUCIA software, version 4.71, Laboratory Imaging, Prague, Czech Republic).

\section{Statistical Analysis}

Results are presented as means \pm standard error of the mean (means \pm SEM) and analyzed using an unpaired Student's $t$ test or by one-way analysis of variance (ANOVA) followed by a Newman-Keuls multiple range test. In all cases, a probability level of $P<.05$ was considered significant.

\section{RESULTS}

\section{Developmental Profiles of Placental 11HSD1 and 11HSD2}

The relative abundance of 11HSD1 mRNA and 11HSD2 mRNA was assessed using quantitative RT-PCR. When plotted according to the day of gestation, a dramatic decrease in 11HSD1 transcript levels was observed between days E13 and E14 followed by a smaller insignificant reduction in the following days (Figure 1). In contrast, placental 11HSD2 mRNA was more abundantly expressed during the last third of gestation and decreased from days E13 to E21, when expression was reduced to $\sim 50 \%$. The mean level of $11 \mathrm{HSD} 2$ protein decreased with advancing gestation to reach its lowest value in the last measurement before term (Figure 2).

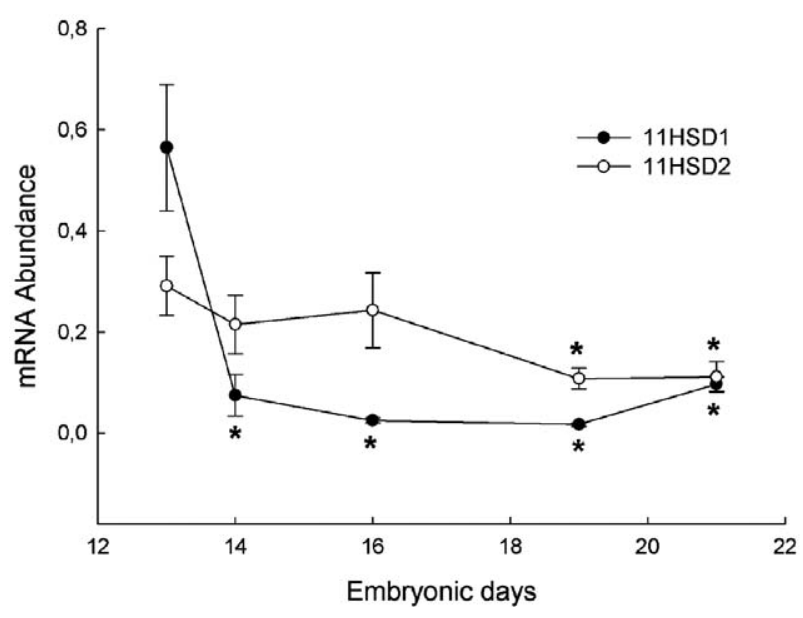

Figure 1. Gestation-related changes in placental abundance of 11HSD1 mRNA and 11HSD2 mRNA. Expression was measured using quantitative RT-PCR, and results are given as relative abundance compared with that of $\beta$-actin. Data are means \pm SEM of 5 to 7 placentae in each group. ${ }^{\star}$ Significantly different from younger stages $(P<.05)$.

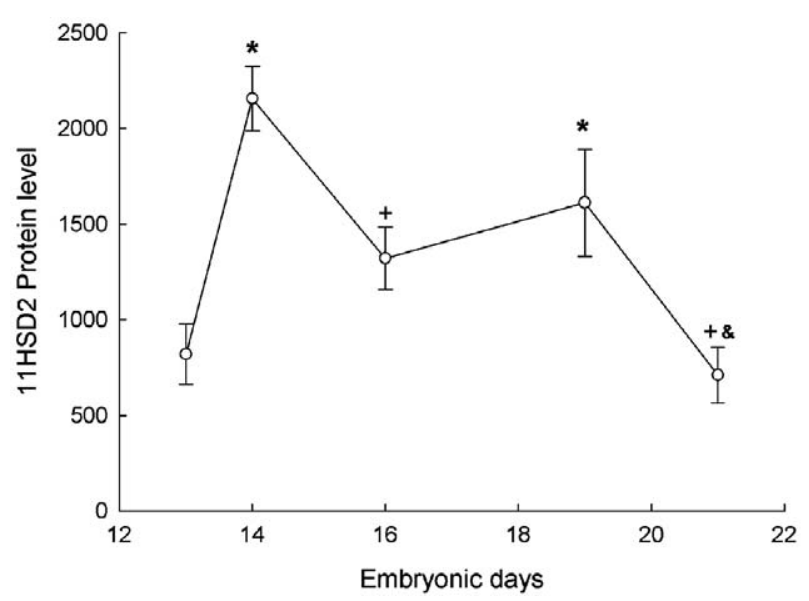

Figure 2. Gestation-related changes in placental 11HSD2 protein levels. Relative protein levels were measured by Western blot and computer-assisted densitometry based on chemiluminescence detection. Data are means \pm SEM of 5 to 9 placentae in each group. ${ }^{\star}$ Significantly different from E13, ${ }^{+}$from E14 and ${ }^{8}$ from E19 $(P<.05)$.

To assess whether these changes in 11HSD1 and 11HSD2 mRNAs are associated with changes in enzyme activities, the conversion of $\left[{ }^{3} \mathrm{H}\right]$ corticosterone to $\left[{ }^{3} \mathrm{H}\right] 11$ dehydrocorticosterone and vice versa was measured in the presence of their respective cosubstrates. Placental $11 \beta$-hydroxysteroid dehydrogenase displayed an increase in $\mathrm{NAD}^{+}$-dependent $11 \beta$-oxidase activity but a decrease in $\mathrm{NADP}^{+}$-dependent $11 \beta$-oxidase activity, respectively 


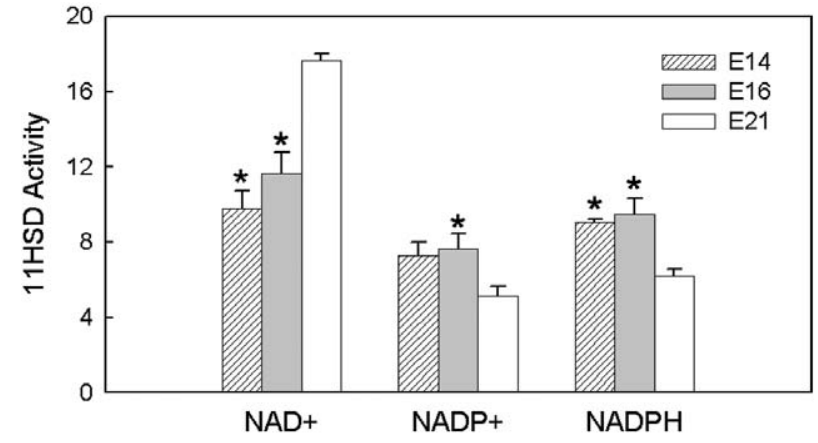

Figure 3. Oxidation of $\left[{ }^{3} \mathrm{H}\right]$ corticosterone $\left(\mathrm{NAD}^{+}\right.$and $\mathrm{NADP}^{+}$) and reduction of $\left[{ }^{3} \mathrm{H}\right] 11$-dehydrocorticosterone (NADPH) in placental homogenates on days E14, E16, and E21 of gestation. The enzymatic activity is expressed as picomoles of corticosterone or 11-dehydrocorticosterone per hour and milligrams of protein and the values are means \pm SEM for 10 to 16 placentae in each group. $\star$ Significantly different from E21 $(P<.05)$.

(Figure 3). In the presence of $\mathrm{NADP}^{+}$, the placental $11 \beta$ oxidase activity had a similar value to the NADPHdependent 11-reductase activity and both activities showed a similar developmental profile during gestation. In all assays, HPLC analysis showed only two peaks corresponding to corticosterone and 11-dehydrocorticosterone and no other metabolites were identified (not shown). These results indicate that the placenta is bidirectional and its ability to inactivate corticosterone is more obvious immediately before term than at the beginning of the last third of gestation.

The immunoreactivity of 11HSD2 was markedly detected in both the junctional and labyrinth zone of rat placenta throughout gestation. Figure 4A and B shows that in the labyrinth zone, the most intense staining was found in the cytoplasm of the differentiated syncytiotrophoblast cells on day E13. The fetal erythroblasts were also positive for 11HSD2. In the junctional zone, weak 11HSD2 positivity was found in the spongiotrophoblast and in the giant cells. On day E16 (Figure 4C and D), the differentiated syncytiotrophoblast of the labyrinth zone was well established. 11HSD2 was found in syncytiotrophoblast I along the interhemal membrane between the maternal space and fetal capillaries. Lower positivity was found in the cytoplasm of the spongiotrophoblast and trophoblast giant cells of the junctional zone. The mature placenta with completely established components of the labyrinth is shown on E19 (Figure 4E) and E21 (Figure 4F). 11ß-HSD2 positivity was found in the syncytiotrophoblast I.

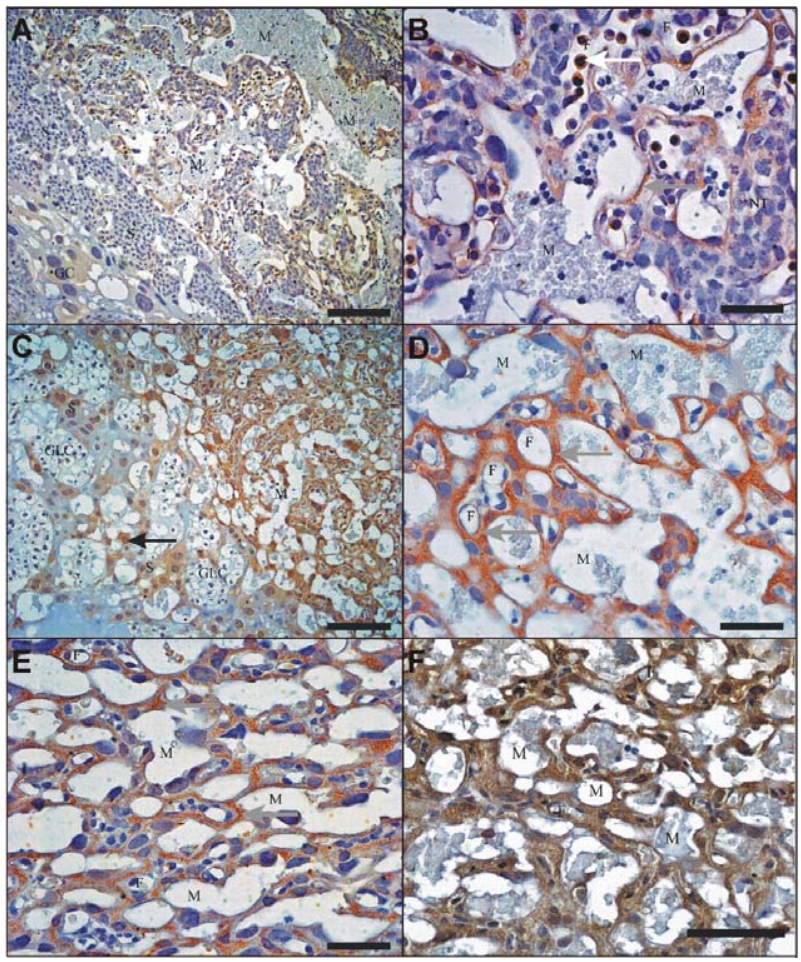

Figure 4. Immunohistochemical localization of 11HSD2 on days E13 (A, B), E16 (C, D), E19 (E), and E21 (F) of gestation. Bars: A and C, $150 \mu \mathrm{m} ; \mathrm{B}, \mathrm{D}$, and E, $75 \mu \mathrm{m} ; \mathrm{F}, 100 \mu \mathrm{m}$. M, maternal lacunae; F, fetal capillaries; GLC, glycogen cells; S, spongiotrophoblast; GC, giant cells; NT, nondifferentiated trophoblast. Black arrow, 11HSD2 in spongiotrophoblast; gray arrows, 11HSD2 in syncytiotrophoblast; white arrow, erythroblasts.

\section{Effect of DTT on Placental 11HSD2}

A comparison of the developmental profiles of 11HSD2 mRNA (Figure 1), protein (Figure 2) and $\mathrm{NAD}^{+}$dependent $11 \beta$-oxidase activity (Figure 3 ) indicated that 11HSD2 might be subjected to regulation at a posttranslational level. To obtain further insight into the posttranslational regulation of $11 \mathrm{HSD} 2$, we studied the effect of DTT on 11HSD2 activity, because dimerization has recently been shown to bring about 11HSD2 inactivation. ${ }^{25,26}$ As shown in Figure 5, DTT stimulated 11HSD2 activity and this effect was concentration-dependent. In addition, placental 11HSD2 was more sensitive to this reducing agent immediately before term than in younger stages of gestation. 


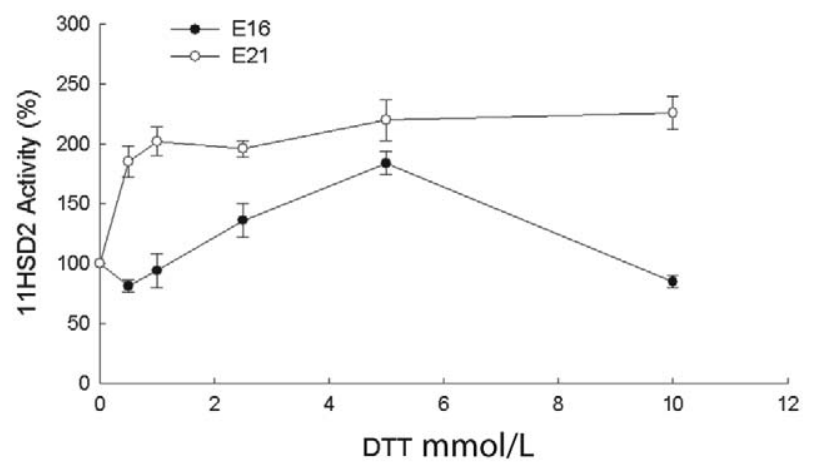

Figure 5. Effect of dithiothreitol (DTT) on 11HSD2 activity in placental microsomes on days E16 and E21 of gestation. The activity of 11HSD2 was measured as $\mathrm{NAD}^{+}$-dependent conversion of $\left[{ }^{3} \mathrm{H}\right]$ corticosterone to $\left[{ }^{3} \mathrm{H}\right] 11$-dehydrocorticosterone. Values are means \pm SEM of 3 experiments.

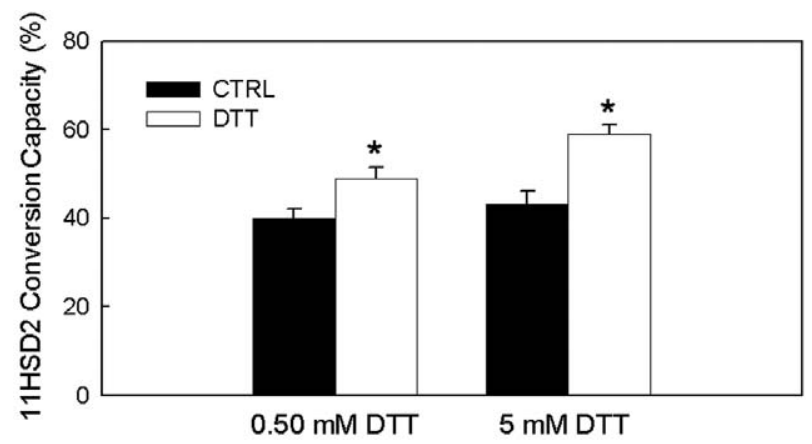

Figure 6. Effect of dithiothreitol (DTT) on 11HSD2 conversion capacity of perfused rat placenta on day 21 of gestation. Corticosterone was infused to the placenta from the maternal side at a concentration of $50 \mathrm{nmol} / \mathrm{L}$. After 10 minutes, DTT was added to the maternal reservoir to reach a concentration of 0.5 or $5 \mathrm{mmol} / \mathrm{L}$. Fetal effluent was sampled and analyzed for corticosterone and 11-dehydrocorticosterone and the conversion capacity was calculated as described in the section Materials and Methods. Data are given as means \pm SEM of 6 experiments. ${ }^{\star}$ Significantly different from control period $(P<.05)$.

To test the possibility that disulfide bonds are able to modulate 11HSD2 activity in intact organs, we performed experiments with isolated placentae. The placenta was perfused with corticosterone $(50 \mathrm{nmol} / \mathrm{L})$ without and subsequently with DTT $(0.5$ or $5 \mathrm{mmol} / \mathrm{L})$ and the placental 11HSD2 conversion capacity was estimated. In this study, DTT at concentrations of 0.5 and $5 \mathrm{mmol} / \mathrm{L}$ caused an increase in 11HSD2 conversion capacity by $21.8 \%$ and $22.2 \%$, respectively (Figure 6).

\section{Effect of Gestation on the Distribution of $\left[{ }^{3} \mathrm{H}\right]$ Corticosterone to the Fetus and the Activity of 11HSDs in Fetal Tissue}

To determine the transplacental transfer of corticosterone and its metabolism in the fetoplacental unit, we measured the local concentration of radioactivity in maternal plasma and the fetus during steady-state infusion of $\left[{ }^{3} \mathrm{H}\right]$ corticosterone. This steady-state plasma concentration was reached on the 30th minute after the initiation of infusion into the dam, lasted at least 30 minutes, and $\sim 90 \%$ of this maternal plasma radioactivity remained in the form of $\left[{ }^{3} \mathrm{H}\right]$ corticosterone. Tritiated 11-dehydrocorticosterone represented approximately $9 \%$ to $10 \%$ of the labeled corticosterone (Figure 7B) and the ratio of $\left[{ }^{3} \mathrm{H}\right]$ corticosterone to $\left[{ }^{3} \mathrm{H}\right] 11$-dehydrocorticosterone in maternal plasma did not change during gestation. However, in the fetuses, the ratio of tritiated corticosterone to 11-dehydrocorticosterone was significantly lower than in maternal plasma and increased with gestational age (Figure 7A; E16, 62/38; E21, 81/19).
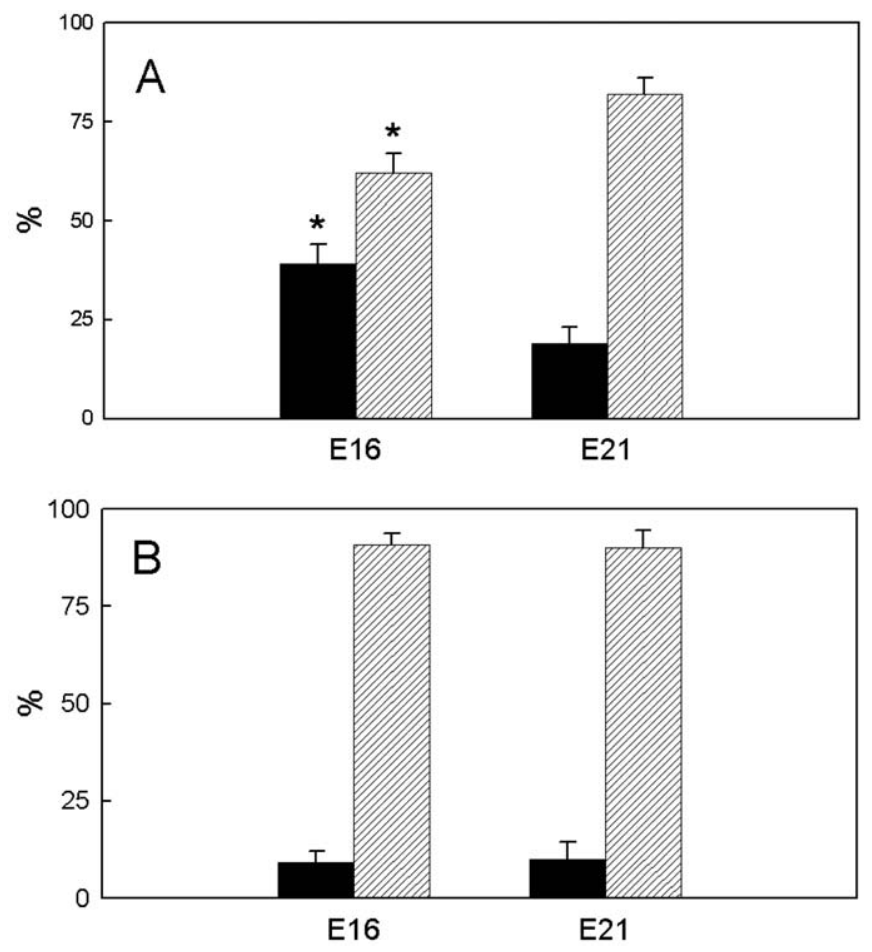

Figure 7. Percentage of $\left[{ }^{3} \mathrm{H}\right]$ corticosterone (hatched columns) and $\left[{ }^{3} \mathrm{H}\right] 11$-dehydrocorticosterone (black columns) in fetus (A) and maternal plasma (B) expressed as a percentage of total corticosterone and 11-dehydrocorticosterone radioactivity at steady state. Values are means \pm SEM ( 3 to 4 animals per group). ${ }^{\star} P<.05$ compared with value at $\mathrm{E} 21$. 


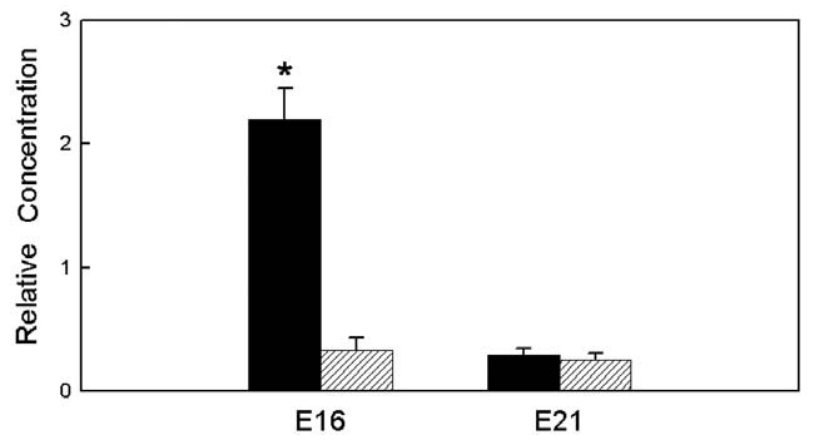

Figure 8. Effect of gestation on the steady-state concentration of $\left[{ }^{3} \mathrm{H}\right]$ corticosterone (hatched columns) and $\left[{ }^{3} \mathrm{H}\right] 11$-dehydrocorticosterone (black columns) in the fetus during infusion of tritiated corticosterone. Relative tissue concentration was calculated as disintegrations per gram (DPM/g) fetal tissue divided by DPM per milliliter $(\mathrm{DPM} / \mathrm{mL})$ of maternal plasma. Values represent the mean \pm SEM of 9 fetuses per group. ${ }^{\star} P<.05$ compared with value at E21.

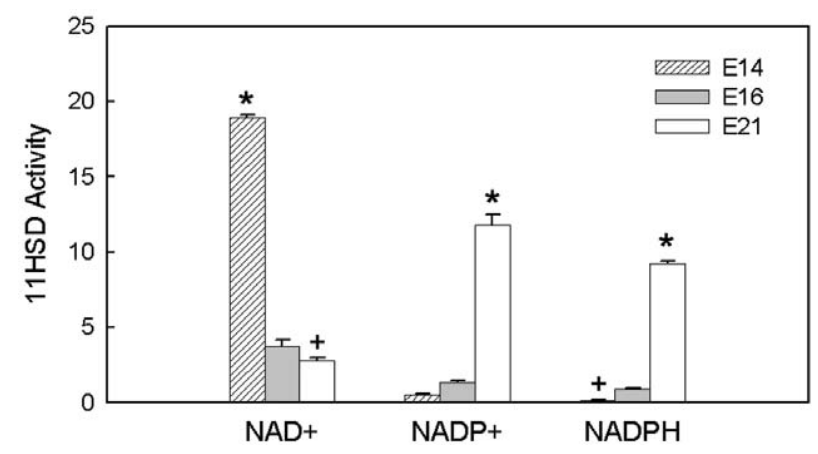

Figure 9. Oxidation of $\left[{ }^{3} \mathrm{H}\right]$ corticosterone $\left(\mathrm{NAD}^{+}\right.$and $\left.\mathrm{NADP}^{+}\right)$and reduction of $\left[{ }^{3} \mathrm{H}\right] 11$-dehydrocorticosterone (NADPH) in homogenates of fetuses on days E14, E16, and E21 of pregnancy. The enzymatic activity is expressed as picomoles of corticosterone or 11-dehydrocorticosterone per hour and milligram of protein and the values are means \pm SEM of 15 to 19 fetuses per group. * Significantly higher than in other ages and ${ }^{+}$significantly different from E16 $(P<.05)$.

The steady-state fetal concentration of $\left[{ }^{3} \mathrm{H}\right] 11$-dehydrocorticosterone relative to that of maternal plasma was significantly higher on day E16 than before term (Figure 8) and this developmental pattern corresponded to that of fetal and was opposite to that of placental 11HSD2 activities (Figures 3 and 9).

\section{DISCUSSION}

Fetal development is associated with a markedly different fetal concentration of biologically active glucocorticoids, cortisol, and corticosterone, than is in the maternal blood. In human and other mammals this maternal concentration is several times higher than the corresponding value in the fetus. ${ }^{8,27}$ In the middle stage of gestation, the rat fetal plasma concentration of corticosterone reaches a value approximately 100 times lower than the maternal plasma and even though the fetal concentration increases during the final third of gestation, its level is always lower than the corresponding maternal one. ${ }^{22,28}$ The reason these relatively low levels are maintained is in part due to the absence of a functional fetal hypothalamic-pituitaryadrenal axis that starts to operate after E16, ${ }^{29,30}$ and in part because of the transplacental barrier to the transfer of maternal corticosterone to fetuses together with the corticosterone metabolism in fetoplacental unit. As we have shown recently, this barrier in rats is not complete ${ }^{6}$ and the dams of rat contribute to the fetal corticosterone concentration to a similar extent as was shown for cortisol in other mammals. ${ }^{8,31}$

This study confirms and extends the previous observations by others that placental tissue is able to convert biologically active glucocorticoids to their inactive derivatives and vice versa and that this metabolic capacity undergoes developmental changes. 11HSD1 has been shown to progressively increase in baboon and porcine placenta ${ }^{14,21}$ but to decrease in rats. ${ }^{32}$ Similarly, 11HSD2 increases during gestation in humans, baboons, and swine $e^{14,21,33}$ but decreases in mice. ${ }^{19,20}$ The rat data remain controversial. ${ }^{28,32,34}$ This discrepancy might result from the various methods used to estimate the developmental profiles of both enzymes (mRNA, protein level, enzyme activity in homogenates or in intact tissue slices) and from the fact that the previous papers were not able to reliably estimate 11-reductase activity as a measure of 11HSD1 in placental homogenates. ${ }^{18,32}$ This study demonstrates that both mRNA and the protein level of 11HSD2 decrease with advancing gestation and reach their lowest values in the days immediately before term. However, these results are inconsistent with the discovery of 11HSD2 activity in placental homogenate. This activity increased during gestation in a similar way to the ability of placental tissue slices to convert corticosterone to 11-dehydrocorticosterone. ${ }^{32}$ Whereas $11 \mathrm{HSD} 2$ is unable to use $\mathrm{NADP}^{+}$as a cosubstrate, 11HSD1 is able to bind and use both $\mathrm{NAD}^{+}$as $\mathrm{NADP}^{+}$(preferential substrate) ${ }^{35}$ such that $\mathrm{NAD}^{+}$-dependent $11 \beta$-oxidation reflects both 11HSD2 and 11HSD1. However, 2 findings indicate that the activity of placental 11HSD2 is upregulated during gestation. First, $\mathrm{NADP}^{+}$-dependent $11 \beta$-oxidase activity 
is nearly identical to NADPH-dependent 11-reductase activity whereas $\mathrm{NAD}^{+}$-dependent $11 \beta$-oxidase activity is significantly higher. Second, the developmental patterns of $\mathrm{NAD}^{+}$-dependent $11 \beta$-oxidase activity is opposite to those of $\mathrm{NADP}^{+}$-dependent $11 \beta$-oxidase and $\mathrm{NADPH}$-dependent 11-reductase. The $\mathrm{NAD}^{+}$-dependent activity increases whereas $\mathrm{NADP}^{+}$-dependent and NADPH-dependent activities decrease during gestation. The data presented here thus support the possibility that, in addition to the genomic regulation of $11 \mathrm{HSD} 2$, there is also a posttranslational regulation of this enzyme. Such regulation has been proposed by the formation of inactive dimers that act as a latent form of $11 \mathrm{HSD} 2 .{ }^{25,26,36}$ The results of this study indicate that a similar mechanism may also operate in placenta and thus a regulated, reversible dimerization and monomerization of 11HSD2 molecules could serve as a mechanism of rapid modulation of placental enzymatic activity. However, the finding that DTT more effectively increased enzyme activity at E21 than at earlier stages, suggests that dimerization was higher at E21 than at E16, yet activity at E21 was relatively high compared with protein level at this time. Additionally, prostaglandins have been recently shown to attenuate 11HSD2 activity without any alteration of 11HSD2 mRNA in JEG-3 cells, a syncytiotrophoblastlike cell line derived from human choriocarcinoma. ${ }^{37}$ Taken together, these data indicate that stimulation of placental 11HSD2 at the end of gestation is mediated by a novel mechanism that does not involve monomerization of 11HSD2.

The coexpression of 11HSD2 and 11HSD1 in the placenta suggests that 11HSD1 might also modulate the transplacental transfer of corticosterone. If we accept the general consensus that $11 \mathrm{HSD} 1$ acts as an 11-reductase converting 11-dehydrocorticosterone to corticosterone, we cannot exclude the possibility that placental 11HSD1 might contribute to the placental delivery of maternal glucocorticoids to the fetus. Because 11-oxo derivatives of glucocorticoid hormones are not bound to plasma binding proteins there is abundant free 11-dehydrocorticosterone at a tens of nanomolar concentration in maternal blood $^{38}$ that could be a substrate for placental 11HSD1 during transfer of maternal 11-dehydrocorticosterone to fetal circulation. Nevertheless, the experiments with perfused human placenta showed that the percentage of cortisol formation from cortisone is much less than the formation from the same dose of cortisol infusion or that 11 -reductase activity is completely absent. ${ }^{4,5}$
Our study provides direct evidence that glucocorticoids of maternal origin are able to access the fetal compartment and corticosterone either partially escapes its inactivation to 11-dehydrocorticosterone in the fetoplacental unit or 11-dehydrocorticosterone is reactivated to corticosterone via fetal 11HSD1. However, the activity of fetal 11HSD1 is very low in E16 whereas 11HSD2 is relatively high. Thus, it is reasonable to consider that some maternal corticosterone in younger stages of placenta escapes its inactivation. Even if the amount of glucocorticoids transferred across the placenta is generally low, ${ }^{8}$ maternal glucocorticoids that transverse the placenta before the activation of ACTH secretion and maturation of the adrenal corticosteroid metabolism seem to be the only glucocorticoid hormones in the fetal compartment. In rats, it has been found that fetal adrenocorticotropic activity begins to secrete ACTH on days E17 and E18, which is also when the fetal adrenal gland gains the ability to synthesise corticosteroids. ${ }^{29,30}$ Thus, it is reasonable to consider that the corticosterone in the rat fetus before E17 is of maternal origin. Based on analysis of the extractable radioactivity, it is obvious that the ratio of corticosterone to 11-dehydrocorticosterone in fetuses on E16 is much smaller that in maternal plasma and also smaller than this ratio on E21. Hence, the fetoplacental unit in earlier stages of gestation appears to provide a greater capacity to inactivate maternal corticosterone. The upregulation of corticosterone oxidation in the earlier stages of gestation is consistent with the increased steady-state concentration of $\left[{ }^{3} \mathrm{H}\right] 11$-dehydrocorticosterone in the fetus relative to that in maternal plasma. If we consider the silencing of 11HSD1 and considerable 11HSD2 activity in the fetus during earlier stages of gestation and much lower activity of fetal 11HSD2 at the end of gestation together with the upregulation of 11HSD1 activity, these findings suggest that fetal 11HSD2 plays an important role in excluding maternal corticosterone from fetal tissue in the earlier stages of gestation. In agreement with this, Brown et $\mathrm{al}^{19}$ found a widespread abundance of 11HSD2 mRNA in mouse embryo from E9 to E12 that dropped to low or undetectable levels between E12.5 and E13.5 (term E19).

There seems to be a different situation at the end of gestation, when endogenous corticosterone acts as a powerful morphogenetic factor, influencing the development of a range of processes in the fetus. ${ }^{1}$ Fetal 11HSD2 is dramatically decreased and 11HSD1 increased (Figure 9), primarily due to changes in the lung and liver, ${ }^{39-41}$ and in 
addition, endogenous corticosterone production by the fetal adrenal gland is increased. ${ }^{29}$ The concentration of fetal $\left[{ }^{3} \mathrm{H}\right] 11$-dehydrocorticosterone was significantly lower in E21 fetuses than in E16 fetuses, which is consistent with the decreased 11HSD2 and increased 11HSD1 activities in fetuses between E16 and E21. Thus, the fetus instead of placenta seems to have a more important role in glucocorticoid metabolism in fetoplacental unit at the end gestation

In summary, this study demonstrates the developmental changes in placental and fetal 11HSD1 and 11HSD2 in the last third of gestation and suggests that both the placental barrier and the oxidation of corticosterone within the fetoplacental unit are able to protect the fetus against maternal glucocorticoids. This protective function seems to play a more important role at the beginning of the last third of gestation than immediately before term, and both placental and fetal $11 \beta$-oxidation of glucocorticoids is involved in this process. Moreover, this study suggests that in addition to transcriptional regulations, placental 11HSD2 activity may be regulated in vivo by dimer-monomer formation. Collectively, these data emphasize, how the developmental alterations of glucocorticoid metabolism in placenta and fetus may influence the fetal concentration of biologically active glucocorticoids. Further studies will be required to determine the direction of 11HSD1 reaction in placental and fetal tissues in vivo. Recent findings show that the activity of 11HSD1 switches from an oxidase to a reductase upon coexpression with the enzyme hexose-6-phosphate dehydrogenase that is thought to modulate the local concentration of nucleotide cosubstrates and is closely associated with 11HSD1 in the membrane of endoplasmic reticulum. ${ }^{42,43}$

\section{ACKNOWLEDGMENTS}

We thank Mrs I. Mezteková and I. Muricová for technical assistance.

\section{REFERENCES}

1. Fowden AL, Forhead AJ. Endocrine mechanisms of intrauterine programming. Reproduction. 2004;127:515-526.

2. Challis JR, Sloboda D, Matthews SG, et al. The fetal placental hypothalamic-pituitary-adrenal (HPA) axis, parturition and post natal health. Mol Cell Endocrinol. 2001;185:135-144.

3. Alfaidy N, Li W, MacIntosh T, Yang K, Challis J. Late gestation increase in 11ß-hydroxysteroid dehydrogenase 1 expression in human fetal membranes: a novel intrauterine source of cortisol. J Clin Endocrinol Metab. 2003;88:5033-5038.

4. Benediktsson R, Calder AA, Edwards CR, Seckl JR. Placental $11 \beta$-hydroxysteroid dehydrogenase: a key regulator of fetal glucocorticoid exposure. Clin Endocrinol. 1997;46:161-166.

5. Sun K, Adamson SL, Yang K, Challis JR. Interconversion of cortisol and cortisone by $11 \beta$-hydroxysteroid dehydrogenases type 1 and 2 in the perfused human placenta. Placenta. 1999;20:13-19.

6. Staud F, Mazancová K, Mikšík I, Pávek P, Fendrich Z, Pácha J. Corticosterone transfer and metabolism in the dually perfused rat placenta: effect of $11 \beta$-hydroxysteroid dehydrogenase type 2. Placenta. 2006;27:171-180.

7. Beitins IZ, Bayard F, Ances IG, Kowarski A, Migeon CJ. The metabolic clearance rate, blood production, interconversion and transplacental passage of cortisol and cortisone in pregnancy near term. Pediatr Res. 1973;7:509-519.

8. Klemcke HG. Placental metabolism of cortisol at mid- and late gestation in swine. Biol Reprod. 1995;53:1293-1301.

9. Venihaki M, Carrigan A, Dikkes, Majzoub JA. Circadian rise in maternal glucocorticoid prevents pulmonary dysplasia in fetal mice with adrenal insufficiency. Proc Natl Acad Sci U S A. 2000;97:7336-7341.

10. Seckl JR. Glucocorticoid programming of the fetus; adult phenotypes and molecular mechanisms. Mol Cell Endocrinol. 2001;185:61-71.

11. Seckl JR, Holmes MC. Mechanisms of disease: glucocorticoids, their placental metabolism and fetal "programming" of adult pathophysiology. Nat Clin Pract Endocrinol Metab. 2007;3:479-488.

12. Krozowski Z, Maguire JA, Stein-Oakley AN, Dowling J, Smith RE, Andrews RK. Immunohistochemical localization of the $11 \beta$-hydroxysteroid dehydrogenase type II enzyme in human kidney and placenta. J Clin Endocrinol Metab. 1995;80:2203-2209.

13. Sun K, Yang K, Challis JR. Differential expression of $11 \beta$ hydroxysteroid dehydrogenase types 1 and 2 in human placenta and fetal membranes. J Clin Endocrinol Metab. 1997;82:300-305.

14. Pepe GJ, Babischkin JS, Burch MG, Leavitt MG, Albrecht ED. Developmental increase in expression of the messenger ribonucleic acid and protein levels of 11ß-hydroxysteroid dehydrogenase types 1 and 2 in the baboon placenta. Endocrinology. 1996;137:5678-5684.

15. Pepe GJ, Burch MG. Albrecht ED. Expression of the $11 \beta$ hydroxysteroid dehydrogenase types 1 and 2 proteins in human and baboon placental syncytiotrophoblast. Placenta. 1999;20:575-582.

16. Roland BL, Funder JW. Localization of $11 \beta$-hydroxysteroid dehydrogenase type 2 in rat tissues: in situ studies. Endocrinology. 1996;137:1123-1128.

17. Burton PJ, Smith RE, Krozowski ZS, Waddell BJ. Zonal distribution of $11 \beta$-hydroxysteroid dehydrogenase types 1 and 2 
messenger ribonucleic acid expression in the rat placenta and decidua during late pregnancy. Biol Reprod. 1996;55:1023-1028.

18. Waddell BJ, Benediktsson R, Brown RW, Seckl JR. Tissuespecific messenger ribonucleic acid expression of $11 \beta$-hydroxysteroid dehydrogenase types 1 and 2 and the glucocorticoid receptor within rat placenta suggests exquisite local control of glucocorticoid action. Endocrinology. 1998;139:1517-1523.

19. Brown RW, Diaz R, Robson AC, et al. The ontogeny of $11 \beta$ hydroxysteroid dehydrogenase type 2 and mineralocorticoid receptor gene expression reveal intricate control of glucocorticoid action in development. Endocrinology. 1996;137:794-797.

20. Thompson A, Han VK, Yang K. Spatial and temporal patterns of expression of $11 \beta$-hydroxysteroid dehydrogenase types 1 and 2 messenger RNA and glucocorticoid receptor protein in the murine placenta and uterus during late pregnancy. Biol Reprod. 2002;67:1708-1718.

21. Klemcke HG, Christenson RK. Porcine placental 11ßhydroxysteroid dehydrogenase activity. Biol Reprod. 1996;55: 217-223.

22. Lesage J, Blondeau B, Grino M, Breant B, Dupouy JP. Maternal undernutrition during late gestation induces fetal overexposure to glucocorticoids and intrauterine growth retardation, and disturbs the hypothalamo-pituitary adrenal axis in the newborn rat. Endocrinology. 2001;142:1692-1702.

23. Mazancová K, Mikšík I, Kuneš J, Pácha J. Placental 11ßhydroxysteroid dehydrogenase in Dahl and spontaneously hypertensive rats. Am J Hypertens. 2003;16:401-406.

24. Pácha J, Mikšík I, Mrnka L, et al. Corticosteroid regulation of colonic ion transport during postnatal development: methods for corticosteroid analysis. Physiol Res. 2004;53:S63-S80.

25. Gomez-Sanchez EP, Ganjam V, Chen YJ, Liu Y, Clark SA, Gomez-Sanchez CE. The 11 $\beta$-hydroxysteroid dehydrogenase 2 exists as an inactive dimer. Steroids. 2001;66: 845-848.

26. Niu P,Yang K. The $11 \beta$-hydroxysteroid dehydrogenase type 2 activity in human placenta microsomes is inactivated by zinc and the sulfhydryl modifying reagent $N$-ethylmaleimide. Biochim Biophys Acta. 2002;1594:364-371.

27. Pepe GJ,Albrecht ED.Actions of placental and fetal adrenal steroid hormones in primate pregnancy. Endocr Rev. 1995;16:608-648.

28. Diaz R, Brown RW, Seckl JR. Distinct ontogeny of glucocorticoid and mineralocorticoid receptor and $11 \beta$-hydroxysteroid dehydrogenase types I and II mRNAs in the fetal rat brain suggest a complex control of glucocorticoid actions. $J$ Neurosci. 1998;18:2570-2580.

29. Dupouy JP. Responses of rat fetal adrenals to synthetic adrenocorticotrophic hormone and $\alpha$-melanocyte-stimulating hormone in-vivo and in-vitro studies.J Endocrinol. 1982;92:23-30.

30. Dupont E, Rheaume E, Simard J, Luu-TheV, Labrie F, Pelletier G. Ontogenesis of $3 \beta$-hydroxysteroid dehydrogenase $/ \Delta 5-\Delta 4$ isomerase in the rat adrenal as revealed by immunocytochemistry and in situ hybridization. Endocrinology. 1991;129:2687-2692.
31. Pepe GJ, Albrecht ED. Transuteroplacental metabolism of cortisol and cortisone during mid- and late gestation in the baboon. Endocrinology. 1984;115:1946-1951.

32. Burton PJ, Waddell BJ. 11 $\beta$-Hydroxysteroid dehydrogenase in the rat placenta: developmental changes and the effects of altered glucocorticoid exposure. J Endocrinol. 1994;143:505-513.

33. Shams M, Kilby MD, Somerset DA, et al.11 $\beta$-Hydroxysteroid dehydrogenase type 2 in human pregnancy and reduced expression in intrauterine growth restriction. Hum Reprod. 1998;13:799-804.

34. Hundertmark S, Bühler H, Fromm M, et al. Ontogeny of $11 \beta$-hydroxysteroid dehydrogenase: activity in the placenta, kidney, colon of fetal rats and rabbits. Horm Metab Res. 2001;33:78-83.

35. Hoffmann F, Maser E. Carbonyl reductases and pluripotent hydroxysteroid dehydrogenases of the short-chain dehydrogenase/ reductase superfamily. Drug Metab Rev. 2007;39:87-144.

36. Gomez-Sanchez EP, Ganjam V, Chen YJ, et al. Regulation of $11 \beta$-hydroxysteroid dehydrogenase enzymes in the rat kidney by estradiol. Am J Physiol. 2003;285:E272-E279.

37. Hardy DB, Pereria LE, Yang K. Prostaglandins and leukotriene B4 are potent inhibitors of $11 \beta$-hydroxysteroid dehydrogenase type 2 activity in human choriocarcinoma JEG-3 cells. Biol Reprod. 1999;61:40-45.

38. Jamieson PM, Walker BR, Chapman KE, Andrew R, Rossiter S, Seckl JR. 11ß-Hydroxysteroid dehydrogenase type 1 is a predominant $11 \beta$-reductase in the intact perfused rat liver. J Endocrinol. 2000;165:685-692.

39. Hundertmark S, Ragosch V, Schein B, et al. Gestational age dependence of $11 \beta$-hydroxysteroid dehydrogenase and its relationship to the enzymes of phosphatidylcholine synthesis in lung and liver of fetal rat. Biochim Biophys Acta. 1994;1210: 348-354.

40. Speirs HJ, Seckl JR, Brown RW. Ontogeny of glucocorticoid receptor and $11 \beta$-hydroxysteroid dehydrogenase type-1 gene expression identifies potential critical periods of glucocorticoid susceptibility during development. J Endocrinol. 2004;181:105-116.

41. Thompson A, Han VK, Yang K. Differential expression of $11 \beta$-hydroxysteroid dehydrogenase types 1 and 2 mRNA and glucocorticoid receptor protein during mouse embryonic development. J Steroid Biochem Mol Biol. 2004;88: 367-375.

42. Bujalska IJ, Draper N, Michailidou Z, et al. Hexose-6-phosphate dehydrogenase confers oxo-reductase activity upon 11ß-hydroxysteroid dehydrogenase type 1. J Mol Endocrinol. 2005;34:675-684.

43. Lavery GG, Walker EA, Draper N, et al.. Hexose-6-phosphate dehydrogenase knock-out mice lack 11ß-hydroxysteroid dehydrogenase type 1-mediated glucocorticoid generation. J Biol Chem. 2006;281:6546-6551. 